\section{$\overline{\substack{\text { hommes } \\ \text { \& migrations }}}$}

\section{Hommes \& migrations}

Revue française de référence sur les dynamiques

migratoires

1285 | 2010

L'appel du pied

\title{
Les pratiques mafieuses dans le recrutement des jeunes footballeurs en Afrique
}

Entretien avec Pierre Cherruau réalisé par Marie Poinsot

Pierre Cherruau et Marie Poinsot

\section{(2) OpenEdition \\ Journals}

Édition électronique

URL : http://journals.openedition.org/hommesmigrations/1182

DOI : 10.4000/hommesmigrations. 1182

ISSN : 2262-3353

Éditeur

Musée national de l'histoire de l'immigration

Édition imprimée

Date de publication : 1 mai 2010

Pagination : 92-97

ISSN : 1142-852X

\section{Référence électronique}

Pierre Cherruau et Marie Poinsot, « Les pratiques mafieuses dans le recrutement des jeunes footballeurs en Afrique », Hommes \& migrations [En ligne], 1285 | 2010, mis en ligne le 29 mai 2013, consulté le 30 avril 2019. URL : http://journals.openedition.org/hommesmigrations/1182 ; DOI :

10.4000/hommesmigrations. 1182 


\section{Les pratiques mafieuses dans le recrutement des jeunes footballeurs en Afrique}

Entretien avec Pierre Cherruau, journaliste à Courrier International, chef du secteur Afrique réalisé par Marie Poinsot

Un jeune et brillant joueur de football africain disparaît durant son transfert d'un club européen vers le Japon. S'il ne s'agissait de l'intrigue d'un roman, on pourrait verser l'événement au compte de l'opacité qui entoure le recrutement des joueurs africains vers l'Europe. Après deux ans

passés au Nigeria, Pierre Cherruau revient sur les liens troubles entre le monde du foot, ses grands clubs, l'argent et la mafia, qui, en Afrique, décident du sort international des surdoués du ballon rond. 
H\&M : Votre roman, Ballon noir ${ }^{(1)}$, s'adresse au public français et mêle une intrigue sur le recrutement d'un jeune footballeur avec la prise en compte des intérêts économiques du Delta du Niger, associés à l'exploitation du pétrole, sur fond de corruption et de violence extrême : pourquoi associer ces thèmes et comment les avez-vous approchés ?

P. C. : Comme beaucoup d'écrivains journalistes, j'ai fait des reportages sur le football au Nigeria en rencontrant de nombreux joueurs et entraîneurs. C'est un sujet que je connaissais particulièrement bien. Le roman noir se doit de s'ancrer dans le réel : on ne peut se contenter d'une intrigue et il faut aller à la source de l'information. Il y a peu de recherches en Grande-Bretagne sur le football africain, alors qu'il y a une immigration nigériane importante. Dans les années soixante et soixante-dix, on ne faisait pas confiance aux footballeurs africains.

En France, le recrutement des footballeurs africains se faisait aussi pour des raisons économiques car les clubs n'avaient pas les moyens financiers des clubs britanniques pour recruter des joueurs de haut niveau. Un certain nombre de joueurs africains ont d'abord fait leurs preuves en France avant d'être recrutés en Grande-Bretagne. Il y avait donc une filière nigériane qui passait par des clubs français ou belges, ou néerlandais. Et, en vertu des relations toujours difficiles entre ex-colonisateurs et excolonisés, le fait de ne pas être britannique était plutôt un atout car il supprimait le contentieux historique.

\section{H\&M : Pourquoi avoir choisi la fiction pour aborder ce thème plutôt que l'essai journalistique?}

P. C. \# Avec la fiction, on peut aller beaucoup plus loin que dans le reportage. Par exemple, je sais que certains matchs sont truqués au Nigeria, avec des arbitres qui vont jusqu'à ne pas publier les scores des matchs. La corruption est très étendue et des gens très importants font des paris sur des matchs, à la fois en Afrique mais aussi en Asie. Mais il est très difficile de recueillir des témoignages sur cette dérive mafieuse. Donc la fiction permet d'être plus proche de la réalité qu'un essai journalistique. Il s'agit moins de dénoncer des individus mais plutôt d'expliquer des structures globales et des modes de fonctionnement. Au Nigeria, on s'aperçoit que les gens sont obligés de jouer le jeu et de fermer les yeux sur un certain nombre de pratiques pour survivre physiquement ou économiquement.

\section{H\&M : Les médias parlent-ils du recrutement de ces jeunes joueurs ?}

P. C. : Les médias commencent à en parler, mais de manière assez anecdotique en évoquant des cas de jeunes recrutés et rackettés par des Européens. Ils se retrouvent dans la rue après un échec dans un club ou un centre de formation. Ils sont démunis 
et souvent ne peuvent pas rentrer chez eux au risque de décevoir leur famille qui a misé sur eux dans tous les sens du terme. Ce qui me dérange dans la façon dont les médias abordent cette question, c'est qu'on oublie la part de responsabilité de l'Occident. Si on parle des gamins à Dakar ou Lagos qui rêvent de venir en Europe, c'est aussi parce que le continent africain est devenu une vaste prison. Or certains jeunes veulent aussi partir pour avoir une expérience de la vie et pas seulement pour s'enrichir. Chez les Peuls, le fait de voyager permet de devenir un homme, c'est un rite initiatique. Mais pour ceux qui n'appartiennent pas à l'élite qui peut aller faire des études en Europe ou aux États-Unis, le mythe du footballeur reste très actif. Pour un garçon des classes populaires ou des classes moyennes, le seul moyen de partir reste de devenir footballeur, comme pour une fille, de devenir une prostituée.

\section{H\&M : Les footballeurs africains ayant fait carrière en France ont long- temps été des étudiants venus y faire leurs études. Avec la fin des visas pour études, la seule liberté des jeunes Africains n'était-elle pas de négocier leur compétence physique et sportive?}

P. C.: Cest pour cela que le sport est une belle métaphore pour évoquer l'évolution des rapports Nord-Sud. On a longtemps dit que l'Afrique échappait à la mondialisation, or le continent africain y revient, mais encore une fois de manière inégalitaire. On s'arrache ses matières premières. L'Afrique reste le terrain d'expression d'une certaine force brute comme du temps de la traite négrière, si on peut tenter cette comparaison. Cela m'avait frappé quand j'étais allé interviewer un grand joueur nigérian qui jouait dans un club français. Son entraîneur français, très connu, m'avait dit que ces joueurs africains étaient très costauds, qu'ils étaient une bonne "race". J'avais l'impression d'entendre un discours de négrier même si le verni est différent.

\section{H\&M : Les agents recruteurs en Afrique sont-ils envoyés par des clubs ou sont-ils surtout des francs-tireurs ?}

P. C.: Il y a un peu de tout. Des aventuriers ou des journalistes qui font des repérages sous couvert de reportages pour les grands clubs. Dans la pratique, agents recruteurs et journalistes se confondent. L'envie de quitter le pays est telle que un Blanc qui débarque dans un club africain est un peu considéré comme le messie qui va permettre aux jeunes de partir en Europe. La vie dans un pays comme le Nigeria est extrêmement violente. D'ailleurs on m'avait raconté qu'un joueur béninois qui jouait dans un club de Lagos avait dû fuir le pays car il sortait, sans le savoir, avec l'ancienne copine d'un gangster local. Les mafias sont extrêmement puissantes et les étrangers peuvent se faire tuer sans s'y attendre. 


\section{H\&M : Les anciens entraîneurs français vont parfois poursuivre leur car- rière en Afrique. N'est-ce pas encore un facteur de stimulation au départ ?}

P. $C_{n}$ : C'est un phénomène intéressant à plus d'un titre. Le choix d'un entraîneur européen montre que les relations coloniales n'ont pas encore disparu. Les joueurs vont davantage accepter l'autorité d'un entraîneur européen qui a aussi certainement de meilleures connaissances dans le domaine technique. Il y a également un facteur plus rationnel : l'entraîneur européen va être considéré plus facilement comme neutre, ce qui n'est pas le cas d'un entraîneur local au Nigeria où le facteur ethnique est tellement important. Si l'entraîneur est Ibo, on va l'accuser de faire jouer plus de Ibos que de Haoussas ou de Yorubas et c'est un sujet extrêmement sensible. D'ailleurs il y a beaucoup de bons joueurs originaires du Sud, du pays Ibo où le football s'est implanté depuis longtemps, alors que dans le Nord musulman, avec la charia, le football était déconsidéré par les imams. En même temps, quand il s'agit de l'équipe nationale, les Haoussas veulent voir jouer des Haoussas. J'avais rencontré un entraîneur dans le Nord dont l'équipe était principalement composée de joueurs ibos 
et le public n'acceptait pas cette sélection. Cela posait des problèmes terribles, surtout avec la recrudescence des conflits ethniques. La composition de l'équipe nationale relève d'une stratégie géopolitique. Le football est tellement important de nos jours en Afrique que les hommes politiques ne peuvent pas s'empêcher d'intervenir. Souvent, l'entraîneur occidental peut constituer une sorte de rempart. Dans un pays comme le Nigeria, les matchs de l'équipe nationale sont les seuls moments fédérateurs avec l'ensemble des ethnies qui soutiennent leur équipe.

\section{H\&M : Est-ce que les joueurs africains sont fatalement condamnés à partir. Peut-on parler d'un phénomène de brain drain sportif ?}

$P_{n} C_{n}$ : Le joueur est éphémère et il va essayer de gagner le plus d'argent le plus vite possible, sachant que sa carrière est fragile et courte. C'est un peu du capitalisme sauvage. En fait, la gestion de la carrière d'un footballeur qui a du succès dans son pays devient très compliquée pour lui, car il est sollicité par énormément de gens et la pression est très forte. A fortiori, quand un joueur africain qui a une belle carrière en Europe revient dans son pays : les attentes sont telles qu'il doit avoir des gardes du corps car on va essayer de l'agresser ou de l'enlever. Lorsque l'équipe nigériane a 
perdu la finale de la Coupe d'Afrique des Nations, à Lagos, face au Cameroun, elle s'est fait agresser par ses supporters. La violence du pays est aussi présente dans les stades. On comprend pourquoi un footballeur nigérian se sent plus en sécurité à Londres qu'à Lagos.

\section{H\&M : Les clubs européens ont-ils conscience des abus qui peuvent être faits dans ces recrutements sauvages? Des formes de régulation sont-elles mises en place?}

P. C. " Il y a eu un changement dans les mentalités grâce à la médiatisation d'un certain nombre de drames. Des centres de formation essayent d'être plus sérieux dans l'éducation de ces jeunes. D'ailleurs, les footballeurs africains sont souvent moins désarmés que les jeunes footballeurs français qui ont quitté très tôt leur famille et peuvent être très naïfs. J'ai interviewé Taribo West qui venait du sud-est du Nigeria puis a fait une carrière à l'AJ Auxerre puis en Italie. Il avait appris à se battre dans les rues de Port Harcourt et n'avait pas peur de foncer comme attaquant. Leur parcours est tellement dur qu'ils peuvent survivre. Les clubs ne rendent pas de compte et ce qui domine est le règne de l'argent. Du moment qu'un joueur est une bonne "gagneuse", personne ne se pose de question.

Ce qui est frappant quand on assiste à un match de football en France, c'est qu'on entend beaucoup de propos racistes parmi les supporters, sauf si le footballeur africain marque un but et gagne. C'est une règle dans le monde du football: l'instrumentalisation des joueurs qui est particulièrement forte quand il s'agit des Africains, quel que soit leur niveau. Le racisme est très présent dans le football. Mais les choses changent : le PSG a pris un entraîneur d'origine canaque et le club de Bordeaux a pris un entraîneur malien (Jean Tigana) ce qui montre que l'on commence à leur faire confiance. C'est un milieu assez conservateur. Les évolutions sont lentes, mais elles se font.

\section{Notes}

1. Pierre Cherruau \& Claude Leblanc, Ballon noir, Marseille, L'Écailler du Sud, coll. "Spéciales" n²1, 2006. 